\title{
MEASURING LOVE AND CARE FOR NATURE
}

\section{H. PERKINS}

\begin{abstract}
This study aimed to develop a psychometrically sound measure of the construct of love and deep caring for nature as an expression of people's personal and explicitly emotional relationship with nature. Expert opinion and pre-pilot surveys were employed for refinement of the item pool, and a sample of 307 university students was used in a major pilot study aiming to further purify scale items. A field trial was conducted using a sample of 261 tourists at leisure with nature. The final 15-item Love and Care for Nature (LCN) scale is differentiated from established measures of similar constructs, and demonstrates high internal consistency and sound validity. This research extends the psychological frameworks of environmental altruism, and has also taken the philosophical concept of biophilia, as love for nature, into the operational realm by making it perceptible and measurable.

Key words: love for nature; caring; environmental altruism; emotional connectedness; pro-environmental behaviour.
\end{abstract}




\section{MEASURING LOVE AND CARE FOR NATURE}

\section{Introduction}

It has been argued that ongoing destruction of the natural environment and degradation of planetary living systems is fast reaching catastrophic proportions, largely as a result of increasing human impact on vulnerable ecosystems and dwindling natural resources (Dietz, Ostrom, \& Stern, 2003; Suzuki, 1997). Within this context of an apparently worsening global ecological crisis, there has recently been a substantial body of literature examining the nature of the human relationship and orientation towards nature and the effects of this on environmental ethics, including indicators of environmental altruism (e.g. Degenhardt, 2002; Mayer \& Frantz, 2004; Nisbett, Zelenski, \& Murphy, 2009; Orr, 2004; Schultz, 2001, 2002). However, a key issue which remains unclear is what motivates individuals to act altruistically in their day to day lives in order to protect the environment, often contrary to their own self interest? This issue is a complex one, and may thus benefit from a more complete understanding through an interdisciplinary approach to the problem (McMichael, Butler, \& Folke, 2003).

\section{The significance of emotions for environmental altruism}

Leopold (1949/ 1987) maintained that all ethics, whatever the type, are founded on the premise that "the individual is a member of a community of interdependent parts” (p. 202). He also argues that to effect a genuine environmental ethic or so-called 'land ethic', we need to fundamentally change our individual and collective psychology - “our intellectual emphasis, loyalties, affections [italics added], and convictions” (p. 210) to include the whole natural environment. Leopold sees the relationship between human emotion and environmental ethics in the following terms:

When we see land as a community to which we belong, we may begin to use it with love and respect. ... That land is a community is the basic concept of 
ecology, but that land is to be loved and respected is an extension of ethics (p. viii).

Seamon (1984) also maintains that environmental ethics is based primarily on

fostering a sense of emotional connectedness with the natural world, and argued for the particular significance of the emotional relationship with nature when he noted: "love and responsibility for the earth cannot only be thought about cerebrally; they must be felt emotionally, with the heart” (p. 769). Callicott (1993) concurs, and expands this concept further by proposing that all morality and ethical systems are based primarily on feelings rather than on reason. Furthermore, it has been argued that the emotion of caring about the environment may be the most important influence on human commitment to act in the interests of nature, and to protect it when under threat (e.g. Clayton, 2003; Orr, 1993; Wilson, 1984, 1993). Orr (1993) also proposes that the extension of an individual's moral concern towards nature is expressed primarily through a pervading affinity for life, or “biophilia” (p. 417).

The concept of biophilia was a term first coined by Fromm (1964), and later expanded by Wilson (1984), to describe a psychological phenomenon of being instinctively attracted to all life. More particularly, Wilson (1984) proposes that the emotional relationship, humans subconsciously seek with the rest of life constitutes the essence of biophilic tendencies, and the very foundation of our drive to cherish and protect all life (pp. 138-139). Fromm (1998) later argues that this innate emotional bond with nature necessarily defines "good” as “a reverence for life, all that enhances life, growth, unfolding” (p. 47), and that the experience of reverence generates a creative and deeply caring attitude (i.e. love) which is the pinnacle of human striving and the basis of all human ethical systems. Human reverence for natural world incorporates the emotions of awe and wonder in the face of the complexity of nature (Carson, 1965; Hepburn, 1984). These emotions are enduring in 
nature and comprise an innate feeling for the high intrinsic value of something, as well as a sense of moral responsibility towards that something; they are thus essentially ‘other’ acknowledging (Carson, 1965; Hepburn, 1984).

However, the emotions of love, awe, wonder, and deep reverence for nature, so strongly associated in the philosophy literature with environmental ethics, have received scant attention from psychological researchers (Klinger, 1998), especially with regard to measurement. Yet this type of measurement research, particularly in relation to examining the role of emotions, as internalized motivations, in fostering environmentally sensitive moral behaviours, is considered an area worthy of attention (Mayer \& Frantz, 2004; Oskamp, 2002). This is because internalized motivations are thought to encourage and maintain more consistent environmentally responsible behaviour, and may be even more effective in this regard than the external incentives and sanctions favoured by many policy makers (Degenhardt, 2002; Kals \& Maes, 2002; Osbaldiston \& Sheldon, 2002).

In view of this, examination of some internalized motivations including the human sense of interconnectedness and community with nature has been the subject of some recent empirical investigation. For example, Schultz (2002) presented a conceptual model of the human sense of interconnectedness with nature and developed a theory of psychological inclusion of nature in one's self concept. Schultz developed the Inclusion of Nature in Self scale (INS), based on a single item pictorial measure with overlapping circles representing the nature and closeness of a person's relationship to nature, in order to operationalise this construct. Schultz (2002) argued that the degree to which a person's cognitive self-concept includes nature also predicts the strength and closeness of the relationship with nature, and is associated 
with pro-environmental values and pro-environmental behaviours (Schultz, 2000, 2002; Schultz, Shriver, Tabanico \& Khazian, 2004).

Mayer and Frantz (2004) also recently developed a multi-item measure, the Connectedness to Nature Scale (CNS), as an extension of Schultz's psychological inclusion of nature in self concept. This scale is purported to measure the emotional aspect of connectedness as a complement to Schultz’s work (Mayer \& Frantz, 2004; Schultz, 2000, 2002). Evidence for the CNS’s construct validity has been demonstrated by its moderately high relationship with Schultz's single item INS (Frantz, Mayer, Norton, \& Rock, 2005; Mayer \& Frantz, 2004), and with other indicators of pro-environmental altruism such as values and beliefs (Mayer, Frantz, Bruehlman-Senecal, \& Dolliver, 2009). However, there is some doubt about its socalled affective or emotional focus, and in a recent report, Perrin and Benassi (2009) have argued that the CNS seems to chiefly measure the more cognitive aspects of connectedness and not the affective dimensions as claimed.

Without negating the usefulness of the established measures of the humannature relationship it seems that most empirical investigations thus far have tended to tap the cognitive aspects of this phenomenon. However, Schultz (2002), Schmuck and Schultz (2002), and Oskamp (2002) have all argued that a more complete understanding of the psychology of the human emotional relationship with nature is both very important and necessary. Furthermore, Schmuck and Schultz (2002) believe that any deficiency in our understanding of the specific role of emotions significantly limits our knowledge of the psychological determinants of proenvironmental altruism in people's day to day lives. Therefore, the aim of this research was to develop a reliable and valid measure of the explicitly affective or 
emotional aspect of the human-nature relationship in order to be able to examine its unique contribution to pro-environmental altruism.

\section{Scale development: Measuring love and care for nature}

\subsection{Defining the construct of love and care for nature}

The construct of love and care for nature is defined in this study as deep love and caring for nature which includes a clear recognition of nature's intrinsic value as well as a personal sense of responsibility to protect it from harm. This definition incorporates the following theoretical dimensions gleaned primarily from the philosophy literature: (1) feelings of awe, wonder and interest in nature, which are sustained emotions said to evoke feelings of care; (2) feelings of love, emotional closeness and interconnectedness with nature, including a spiritual aspect somewhat neglected in the psychology literature; and (3) feelings of care, responsibility and commitment to protect nature.

\subsection{Generation of the item pool}

The aim of this stage of the scale development process was to develop a large number of items, from a domain of all possible items, to ensure adequate redundancy for optimal scale development purposes (see De Vellis, 2003; Hinkin, 1995; Kline, 1998). One hundred item statements were generated incorporating the theoretical dimensions mentioned in the previous section, with a deliberate emphasis on explicit emotional wording or at least emotional connotations wherever possible. An initial purification process for the draft set of items was undertaken in Study 1. 


\section{Study 1 - First stage purification of item pool}

\subsection{Procedure and results}

In accordance with recommendations of De Vellis (2003), a small group of 10 interdisciplinary experts ${ }^{1}$ was recruited and asked to comment in writing via email on each of the items in the pool. Each member of this group was given a working definition of the construct of interest including a summary of its underlying theoretical dimensions, and asked to comment on each item's clarity and conciseness of wording, and whether it had high, medium or low relevance to the construct of interest. Provision was also made for general comments to be recorded after each item. As a result of this feedback, several items were re-worded or eliminated from the item pool, and the remaining 93 items were available for further purification processes. The involvement of a panel of experts in the earliest stage of scale development was to maximise the likelihood of appropriate content validity of the large item pool before a further purification process was undertaken through pre-pilot testing in Study 2.

\section{Study 2 - Second stage purification of item pool}

\subsection{Method}

Ninety-three item statements resulting from Study 1 were subjected to additional purification using a small convenience sample. The aim of this exercise was to reduce the item pool to a more manageable number of around 40 items considered most suitable for the major pilot study of this project while retaining reasonable levels of redundancy for scale development purposes.

\subsubsection{Participants, materials and procedure}

\footnotetext{
${ }^{1}$ This group included a number of senior academics with varied expertise including social marketing, scale development, sociology, environmental education, social and environmental marketing, management, and statistics. The group also included a doctoral student with extensive relevant industry experience, a senior government official in environmental sustainability, and a psychologist.
} 
Participants for a pre-pilot survey were recruited by the researcher who approached colleagues and other university community members asking for volunteers. Fifty-three adults, $44 \%$ male and 56\% female, recruited in this way, completed the 93 item pool as respondents to the survey. These participants were also encouraged to critique both the individual item statements and the scale as a whole. Participants rated the items on a 7-point Likert scale from 1 (strongly disagree) to 7 (strongly agree). The individual item responses were then analysed in terms of item response distributions, means, and standard deviations. Respondents’ comments pertaining to individual item statements, as well as inter-item and item-total correlations, were also examined and considered in the item evaluation process.

\subsection{Results and discussion}

Items with very high means $(M=>6.00)$ and little variability $(S D<1.00)$ were eliminated in the first instance (see De Vellis, 2003). Examples of items that were eliminated in this process included "I feel that I must not waste or degrade natural resources”, "Pollution of air and water is unacceptable”. On reflection, items such as these seem to represent current social values to which most people might strongly support in the current context of global environmental concerns. Social value type items, while undoubtedly related to the construct of interest, probably provide little or no discriminating value in the population, and so are less useful inclusions in a scale measure for research purposes.

Items that participants indicated had ambiguous or unclear wording, together with those with the lowest corrected item-total correlations were also eliminated from the item pool. Some of the latter included pro-environmental behaviour type items which were discarded because they were considered to be most likely measuring potential outcomes or consequences of love and care for nature (e.g. "I feel it is 
important to only buy wood products that are from plantation sources", "I feel it is important to buy recycled paper products whenever possible”), as opposed to being actual measures of the construct itself. The elimination process resulted in a more manageable list of 40 items with the best psychometric properties to be included in a pool for the major pilot testing phase of the research (Study 3). Examples of some of the 40 items included in the pilot study item pool were: "I feel a deep love for nature”, "I feel spiritually bound to the rest of nature”, “I feel joy just being in nature”, "I often feel a powerful sense of awe and wonder in the presence of unspoilt nature”, "I feel a personal sense of interconnectedness with the rest of nature”. The 40 items used for pilot testing were also considered to be still reasonably representative of the three main theoretical dimensions of the construct (see section 3.1).

\section{Study 3 - Third stage purification: Major pilot study}

The aims of the pilot study were: to reduce the number of items to approximately 20 with good psychometric properties; determine the internal consistency of the scale; and to establish some early evidence of its construct validity.

\subsection{Method}

\subsubsection{Participants}

Three hundred and seven university students over the age of 18 years, comprising $62 \%$ females and 38\% males, volunteered to participate without any course credit. This sample was recruited by convenience sampling within a university business school. Business studies students were targeted because it seemed likely that they were more similar to the general population than students of some specialist areas, such as the environmental sciences, engineering, or health and medicine. Volunteer students were asked to complete the questionnaires privately and place 
them anonymously in the confidential envelopes provided which were then sealed and returned to the researcher.

\subsubsection{Materials and procedure}

In addition to the 40-item draft pool for the new Love and Care for Nature (LCN) scale, Schultz's (2002) single item measure (INS) was included in the pilot survey instrument as a validating item. Respondents were asked to respond to individual items of the LCN on a Likert type scale as before. They were also asked to respond to the single item INS scale by marking which of the pairs of circles (labelled “me” and “nature”), ranging from barely touching to completely overlapping, best represented their relationship with nature. Each of the pictures was coded by the researcher from 1 to 7 , with 1 indicating no sense of closeness (i.e. no overlap of the circles) and 7 indicating a complete sense of oneness with nature (i.e. complete overlap of the circles). Possible scores on the INS thus ranged from a low of 1 to a high of 7.

\subsection{Results and discussion}

All data were entered using SPSS statistical software and any negatively worded items were reflected before analysis. Item characteristics such as means, standard deviations, item response distributions, were analysed and those items which demonstrated weak performance such as high means and very low standard deviations were eliminated first. Factor analysis of the item pool yielded similar results to item analysis in this study ${ }^{2}$. When this is the case, Nunnally (1978) has argued that item analysis including evaluation of item-total correlations is appropriately used as the principal means of item elimination in the early purification stages of scale

\footnotetext{
${ }^{2}$ Exploratory factor analysis was initially evaluated using eigenvalues and the scree plot. The first factor, with an eigenvalue of 17.47 , accounted for $43.68 \%$ of the variance in the factor solution. Items loading on the remaining factors were also those eliminated in the early stages through item analysis including assessment of corrected item-total correlations.
} 
development due to the simplicity of this technique and its usefulness for identifying those items which are highly inter-correlated and thus tap a common core. In view of these recommendations, items with the lowest corrected item-total correlations were identified and removed one at a time and the analysis re-run after each removal. This ensured that corrected item-total correlations were all in excess of .50 to maximise the internal consistency and thus reliability of the scale (see Hair, Black, Babin, Anderson \& Tatham, 2006). As expected, Cronbach’s alpha remained very high (> .90) throughout this process. It was interesting to note that the two negatively worded items in the 40-item draft pool (i.e. "I don't really like being in wilderness areas or unspoilt nature”, and “I prefer artificial environments and advanced technology around me”) were eliminated in the first stages of the scale reduction process, with very low corrected item-total correlations of $r=.29$ and $r=.38$ respectively. This tends to support previous reports of the relatively poor psychometric performance of negatively worded items in scale measures (De Vellis, 2003; Hinkin, 1995; Marsh, 1996). Twenty-three items were selected from the initial 40 -item pool for additional testing in the field trial (Study 4) because, at this point, comparing individual item performances became increasingly arbitrary, and it was therefore considered prudent to use the field trial for further assessment of individual scale items, prior to evaluation of reliability and validity.

Scores on the 23-item draft Love and Care for Nature (LCN) scale correlated strongly with the INS scale, $r=.67$, providing some early evidence of the new scale's construct validity, and it also exhibited very high internal consistency $\alpha=.96$.

\section{Study 4 - Evaluation of the new scale: Field trial}

The primary aims of the field trial were: to further shorten the scale due to its very high internal consistency; to evaluate the new scale’s psychometric properties 
including its reliability and validity; and to determine its unique contribution with respect to already established measures of related constructs.

\subsection{Method}

Direct contact with nature during nature based leisure experiences have been argued to generate an increased sense of emotional interconnectedness and love for nature (Kaplan \& Kaplan, 1989; Rolston, 1993; Wilson, 1984). Opportunities for humans to interact directly with nature can be provided by nature tourism experiences, including ecotourism, the seeking of which may also be a manifestation of the deep-seated human need to reconnect with nature proposed by Wilson (1984) and Fromm (1964). Therefore, a field trial using a sample of tourists experiencing nature at some level was considered a useful means of accessing respondents with at least some overt interest in the natural environment.

\subsubsection{Participants}

Two hundred and sixty-one tourists (42\% males and 58\% females) were sampled from two venues in the Gold Coast tourism region in Australia. A convenience sampling approach was employed in order to minimise disruption to tourists' experiences and also reduce any interference with satisfaction levels. The first site was a marine wildlife theme park where nature, in a relatively sanitized context, was a point of interest together with other theme park type attractions. The second site was an accredited ecotourism venue in a national park, where the environmental context was relatively unspoilt and nature was the entire focus of the tourism experience. The venues were chosen with a view to obtaining information that reflected a degree of diversity of likely interest in and concern for nature.

Tourists' ages ranged from 18 to 75 years old, with an average age overall of 41 years. The age profiles of males and females were the same $t(243)=0.24, p$ 
$=.808$, as was the proportion of males and females across both venues $\chi^{2}(1, N=254)$

$=0.031, p=.860$. More than a quarter of the tourists were international visitors.

\subsubsection{Materials and procedure}

The 23-item draft (LCN) scale was administered in the field trial.

Respondents were asked to respond on a 7-point Likert type scale ranging from 1 strongly disagree to 7 strongly agree. In addition, both the CNS and the INS were included for validation purposes, and also for determining the unique contribution of the new LCN with respect to these established measures of environmental connectedness. Respondents were asked to respond to each of the 14 items in the CNS on a 7-point Likert type scale, ranging from 1 strongly disagree to 7 strongly agree. Total scores could range from the lowest possible score of 14 (14 x 1) to the highest possible score of 98 (14 x 7), with higher scores on the CNS being indicative of stronger feelings of connectedness to nature. An alpha score of .86 for the CNS was similar to the results of Mayer and Frantz (2004). The mean score was 4.83, SD $=0.84$ (on a 7 point scale). For the single item INS, respondents were asked to respond as previously described, and scores on the INS ranged from a low of 1 (little relationship) to a high of 7 (very close relationship). The mean score was $4.14, S D=$ 1.46.

The 15-item New Ecological Paradigm (NEP) (Dunlap, Van Liere, Mertig, \& Jones, 2000), an established measure of broad pro-environmental beliefs, was also included in the instrument for validation purposes. Respondents were asked to indicate their opinion for each of the item statements in the NEP using a 7-point Likert type scale, ranging from 1 strongly disagree to 7 strongly agree. Negatively worded were reflected before totals were calculated. Total scores could range from 
the lowest possible score of 15 (15 x 1) to the highest possible score of 105 (15 x 7). Alpha $=.80$. The mean score for the entire sample was $4.99, S D=0.77$.

Environmentally relevant core values have been consistently associated with indicators of environmental altruism (e.g. pro-environmental beliefs, attitudes, behaviour, etc.) yet some values types have been found to have little or no relationship with such indicators (Schultz et al., 2005; Stern, Dietz, \& Guagnano, 1998). The 15-item Brief Inventory of Values (BIV) ${ }^{3}$, developed by Stern et al. (1998), was administered to measure five core values types and test the validity of the new scale, as an indicator of a pro-environmental orientation, in terms its relationships with each of the values types. The five values types included: biospheric and socioaltruistic values from an altruistic values cluster (e.g. "respecting the earth, harmony with other species” and “equality, equal opportunity for all” respectively); conservatism values (e.g. "honouring parents and elders, showing respect”); egoistic values (e.g. “wealth, material possessions, money”); and openness to change values (e.g. “an exciting life, stimulating experiences”). Respondents were asked to indicate how important each of these values are "as a guiding principle in your life, on a scale from 1 (not at all important) to 7 (extremely important)" with $0^{4}$ marked if the respondent was actually opposed to the particular value. In accordance with the recommendations of Schwartz (1992), scores for individual value statements were centred to control for variations in individual response patterns, and then amalgamated for each of the five basic values types.

Following the work of Stern et al. (1999), two items were used to assess respondents' willingness to make personal sacrifices for environmental conservation and protection: "I would be willing to accept cuts in my standard of living in order to

\footnotetext{
${ }^{3}$ Developed from Schwartz's (1992) original List of Values.

${ }^{4}$ See Stern et al. (1998).
} 
protect the environment", "I would be willing to pay much higher prices for many goods and services in order to protect the environment”. Willingness to make personal sacrifices is appropriately conceptualised as a behavioural intention rather than manifest behaviour, however, willingness to act in this manner has been previously shown to be a significant predictor of actual behaviour (Kaiser, Schultz \& Scheuthle, 2007; Kals \& Maes, 2002), and was therefore considered useful as a criterion variable for validity assessment. Respondents were asked to indicate their responses to each of these items on a seven point Likert scale ranging from 1 (strongly disagree) to 7 (strongly agree).

A number of items also adapted from the work of Stern et al. (1998) and Stern et al. (1999) were included to measure self-reported pro-environmental behaviour such as: "how often do you make a special effort to buy paper and plastic products that are made from recycled materials?", "how often do you make a special effort to buy products that are environmentally friendly?”, "how often have you boycotted or avoided buying the products of a company because you felt the company was harming the environment?", "how often do you vote for a candidate in an election at least in part because he or she is in favour of strong environmental protection/ conservation?”. Respondents were asked to note the frequency of these behaviours in their daily lives as: “always”; “mostly”; “occasionally”; “never”. In addition, respondents also indicated whether or not they belonged to an environmental organisation.

\subsection{Results and discussion}

\subsubsection{Shortening the LCN scale}

An important task in reducing the number of items in the LCN scale was to ensure that there were minimal adverse effects on the scale's internal consistency or its usefulness as a measure of the explicitly emotional aspect of the human nature 
relationship. Therefore, reliability analysis and evaluation of the wording in individual item statements were the two primary methods used to further reduce the scale. Consistent with the procedure used for the pilot test data analysis, and for similar reasons, items with the lowest corrected item-total correlations were eliminated from the scale one at a time, and the analysis re-run at each step of the elimination process. Items with higher corrected item-total correlations and containing clear emotional wording or reflecting a more personal relationship with nature were favoured for inclusion in the final 15-item version of the LCN. Retaining 15 items in the new LCN at this stage rather than shortening the scale further seemed appropriate since many other established multi-item measures of related constructs contain approximately 15 items (e.g. NEP, BIV, CNS). Table 1 presents the 15 items of the final LCN scale and their individual corrected item-total correlations. Factor analysis resulted in all 15 items loading on a single factor which accounted for $71.18 \%$ of the variance in the solution ${ }^{5}$, confirming its uni-dimensional nature. The mean of the LCN was 5.36, $S D=1.10$ (on a 7 point scale).

\subsubsection{Reliability assessment}

Cronbach's alpha for the 15-item LCN scale resulting from field trial Study 4 was $\alpha=.97$. Shortening the scale from 23 items to 15 did not adversely affect internal consistency, largely due to the scale purification process undertaken in Study 2 and Study 3 as recommended by Nunnally (1978) and Hair et al. (2006).

\subsubsection{Differentiation of the new LCN Scale from existing CNS and INS scales}

It was an important goal of the field trial to differentiate the new LCN from two previously validated measures of very similar constructs relating to connectedness with nature, namely the Connectedness to Nature Scale (CNS) and the

\footnotetext{
${ }^{5}$ Factor loadings for the individual items ranged from .793 to .878.
} 
Inclusion of Nature in Self scale (INS), in order to confirm the unique contribution of the new Love and Care for Nature scale (LCN), and thus the practical research value of this new measure. Given the theoretical relationships between the INS, the CNS, and the new LCN, it was important to ensure that the already established INS and CNS, and this new LCN scale, were not measuring the same construct, in spite of the previously presented arguments against this. A Principal Components Factor Analysis with oblique rotation was used to determine if most or all of the items in the CNS, INS and the LCN loaded on a single factor, which would indicate too much commonality to warrant continuation of the development of the new LCN scale as distinct from the existing CNS and INS measures.

Emergent factors with eigenvalues greater than 1 resulted in a clear loading of the LCN almost exclusively on one factor, and the CNS and the INS almost exclusively on another factor. The total variance explained for the default factor solution was $69.28 \%$. These data are presented in Table 2 . The results provide some evidence that the new Love and Care for Nature scale (LCN) is indeed differentiated from both the Connectedness to Nature Scale (CNS) and the Inclusion of Nature in Self (INS) measure, even though the underlying constructs being measured are empirically and theoretically related to each other. It could be that these three scales are each measuring different sub-dimensions of a larger underlying multi-dimensional construct, perhaps psychological inclusion in nature. This proposition requires some future investigation.

\subsubsection{Validity assessment}

Assessment of validity of scale measures includes gathering evidence for the following three types of validity: content validity, construct validity, and criterionrelated validity (Cronbach \& Meehl, 1955; De Vellis, 2003; Kline, 1998). Content 
validity is defined as the extent to which a specific set of items seem to reflect the universal content domain (Cronbach \& Meehl, 1955; De Vellis, 2003). The early use of a panel of experts to provide advice and feedback on each of the 100 plus items in terms of the construct of interest (Study 1), in accordance with recommendations of De Vellis (2003), together with the pre-pilot survey (Study 2), maximised the chance that any items used in the later stages of scale development demonstrate appropriate content validity.

Part of the process for assessing construct validity includes assessing convergent validity, or the degree to which a measure is highly related to other similar or theoretically related constructs, and also discriminant validity, or the lack of relationship between a measure and theoretically unrelated constructs (Campbell \& Fiske, 1959; De Vellis, 2003). As expected, the 15-item LCN had strong positive relationships with both scores on the CNS $(r=.79, p=.000 \mathrm{~N}=240)$ and the INS ( $r$ $=.57, p=.000 \mathrm{~N}=229$ ). Moreover, the LCN also had a significant positive relationship with the NEP $(r=.41, p=.000, \mathrm{~N}=248)$. The NEP has been shown to be significantly correlated with pro-environmental values, pro-environmental attitudes, and pro-environmental behaviour (Dunlap et al., 2000; Schultz et al., 2005; Stern, Dietz, \& Guagnano, 1995). The INS and CNS have also been empirically associated with a pro-environmental orientation (e.g. Mayer \& Frantz, 2004; Schultz, 2002). Therefore, the significant relationships between the LCN and the theoretically related NEP, INS, and CNS provide evidence of the new LCN's convergent validity, and thus its construct validity.

Previous research has found that environmentally relevant core values, namely the self-transcendent or altruistic type values are related to pro-environmental concerns, attitudes, and other indicators of environmental altruism (Dietz, Fitzgerald, 
\& Schwom, 2005; Stern et al., 1998). The altruistic type values include two subtypes: a nature sub-type concerned with the wellbeing of nature for its own sake (i.e. the biospheric values), and a general altruistic sub-type, concerned with the wellbeing of humanity without any reference to nature per se (i.e. the socio-altruistic values) (Stern et al., 1998). In contrast, egoistic or self-enhancement type values are consistently associated with less pro-environmental concern, attitudes, and behaviours (Dietz et al., 2005; Stern et al., 1998). As expected, scores on the new LCN scale had a strong positive relationship with the biospheric values $r=.60 \mathrm{~N}=249 p=.000$ and, to a lesser extent, with the socio-altruistic values $r=.21 \mathrm{~N}=249 p=.001$. Moreover, the stronger relationship between the new LCN and the biospheric values represents substantial evidence of the LCN's construct validity, since the LCN is designed as a measure of an individual's deep love and concern for nature for its own sake, logically assumed to be indicative of a biospheric orientation or a strong belief in the intrinsic value of nature. As further evidence of its convergent validity, LCN scores had a significant negative relationship with the importance of egoistic or selfenhancement values $r=-.43 \mathrm{~N}=249 p=.000$, in accordance with both theory and previous empirical findings. It seems that the more love and care for nature individuals express the less importance they tend to place on egoistic concerns. Instead they place more importance on the wellbeing of nature for its own sake. These results provide additional evidence of the construct validity of the LCN scale. Discriminant validity of a scale measure is confirmed through its lack of relationship with theoretically unrelated constructs, and also contributes to the evidence for a scale’s construct validity (Campbell \& Fiske, 1959; De Vellis, 2003). Previous research has found no relationship between the openness to change values and pro-environmental behaviour or willingness to sacrifice to protect the 
environment (Dietz et al., 2005; Stern et al., 1998). Furthermore, while there have been some past reports of a negative association between conservatism (i.e. traditionalism) and environmental altruism, there have been others reporting no association at all, and therefore evidence of any relationship between conservatism and environmental altruism is equivocal at best (Dietz et al., 2005). Consistent with these previous findings, the LCN had no relationship with openness to change values $r=-.02 \mathrm{~N}=249 \mathrm{p}=.697$ in this present field study, and only a non-significant negative relationship with conservatism values $r=-.11 \mathrm{~N}=249 p=.077$. These results provide support for the discriminant validity of the new LCN and add to the evidence of its construct validity.

In determining the criterion-related validity of the new LCN, it was necessary to assess its concurrent validity against "gold standard” criterion variables because all measures used for validation purposes were administered with the LCN simultaneously (De Vellis, 2003). In deciding upon a suitable "gold standard” for assessing the criterion related validity of the new scale, previously tested indicators of environmental altruism were considered to be appropriate including measures of selfreported pro-environmental behaviour, as well as willingness to make personal sacrifices to protect the environment (see Stern et al., 1998). Table 3 presents the correlations between scores on the LCN and the self-reported frequency of various pro-environmental behaviours. Respondents who expressed stronger levels of love and care for nature also tended to report more frequent pro-environmental behaviours, providing some evidence of the concurrent validity of the LCN, and thus its criterionrelated validity.

Additional evidence of the criterion-related validity of the new LCN was assessed through its relationship with respondents’ willingness to make personal 
sacrifices in order to protect the environment. Moreover, it was considered useful to determine the LCN's unique contribution to these criterion variables with respect to the contribution of theoretically related measures such as the CNS and the INS. Establishing the unique contribution of the new LCN in terms of relevant criterion variables provides additional evidence of its differentiation from established measures of similar constructs.

As expected by theory, all three measures had significant associations with respondents’ willingness to make personal sacrifices such as accepting increased costs or cuts in living standard to protect the environment (see Table 4). Multiple regression analysis ${ }^{6}$ revealed that Love and Care for Nature (LCN), the INS, and the CNS were significant combined predictors of both willingness to pay much higher prices for goods and services or to incur cuts in personal living standard in order to protect the environment, and accounted for $31.9 \%$ and $29 \%$ of the variance respectively in each of these criterion variables. However, the LCN made the only significant unique contribution to both willingness to pay higher prices $\beta=.46, p<$ .001 and also willingness to incur cuts in personal living standard $\beta=.43, p<.001$ (refer Table 5). Therefore, it appears that of the three measures of connectedness, love and care for nature (LCN) was the most important predictor of willingness to make personal sacrifices in order to protect the environment. In summary, the LCN was found to be significantly associated with both greater frequency of self-reported pro-environmental behaviours and more willingness to make personal sacrifices to protect the environment. Collectively, these findings provide consistent evidence for the new LCN scale's criterion-related validity, and also of its unique contribution with respect to related measures.

\footnotetext{
${ }^{6}$ Predictor variables were entered into multiple regression analyses simultaneously.
} 


\section{Conclusion}

This new 15-item measure, called the Love and Care for Nature (LCN) scale, aims to reflect the underlying construct of love and care for nature while exhibiting good psychometric properties. During the field trial the LCN was clearly differentiated from previously established and theoretically related measures of similar constructs, namely the Connectedness to Nature Scale (CNS) and the Inclusion of Nature in Self scale (INS). The new 15-item Love and Care for Nature scale (LCN) also had high internal consistency, and there was strong evidence of its validity, including content, construct, and criterion-related validity.

This new instrument, designed to assess the personal and largely emotional relationship humans have with nature, may be useful for empirical research into the differential effect of various psychological determinants of environmental altruism across a range of contexts. In particular, the LCN may prove to be a worthwhile complement to the more cognitive measures of psychological inclusion in nature (e.g. INS or CNS scales) in further investigating the role of psychological connectedness, caring and commitment in environmental altruism, especially behaviour involving more effort and personal sacrifice on the part of individuals. Moreover, love and care for nature seems to be, at least in this sample, a better predictor of people's willingness to make such sacrifices including accepting much higher prices and lower living standards to protect the environment than either the CNS or the INS. Perhaps as more effort and sacrifice is required of us in terms of a demonstrable commitment to environmental protection, the strength of our feelings of love and care about nature could be the defining issue.

The need to make a range of personal sacrifices, particularly in developed nations, may be an increasingly likely scenario for a future where global 
environmental problems are becoming more salient. Environmental philosophers have long proposed that direct experiences in nature, including wilderness and other nature based tourism, wildlife watching and photography, in situ environmental awareness programs, or even community and back-yard gardening projects, can often have profound emotional effects on people. If this is true, then encouraging more of these types of activities within communities may be valuable for increasing our sense of caring for nature, and thus our commitment to environmental protection. The new 15-item LCN may be useful as an evaluation tool for these and similar initiatives, because administration, analysis and interpretation of the instrument are all relatively straightforward, and it may also be used to track changes in people over time.

\subsection{Recommendations for future research}

The results of the development process for the LCN scale are encouraging but should be treated with some caution due to the limitations of the nature of the development samples and convenience sampling procedures employed during scale development. Norm establishment was also beyond the scope of this present research project and therefore extensive further testing of the new Love and Care for Nature (LCN) scale using a wide variety of sampling frames and contexts will be necessary in order to complete the scale development process, and also confirm its reliability, validity, generalisability and practical usefulness.

\section{Acknowledgements}

(to be included in final draft) 
Table 1

Corrected item-total correlations for 15 item LCN

\begin{tabular}{llc}
\hline \multicolumn{1}{c}{ Item } & $\begin{array}{c}\text { Corrected item } \\
\text {-total correlation }\end{array}$ \\
\hline 1. I feel joy just being in nature & .78 \\
2. I feel that closeness to nature is important for my wellbeing & .84 \\
3. When I am close to nature, I feel a real sense of oneness with nature & .86 \\
4. I feel content and somehow at home when I am in unspoilt nature & .83 \\
5. I feel a deep love for nature & .85 \\
6. I often feel emotionally close to nature & .86 \\
7. When I spend time in unspoilt nature I feel that my day-to-day worries & .79 \\
8. Peem to dwindle away in the face of the wonder of nature & .79 \\
9. I feel spiritually bound to the rest of nature & .77 \\
10. I feel a personal sense of interconnectedness with the rest of nature & .84 \\
11. I often feel a sense of awe and wonder when I am in unspoilt nature & .84 \\
12. I often feel a strong sense of care towards the natural environment & .83 \\
13. I need to have as much of the natural environment around me as & .79 \\
14. Whible & .82 \\
15. I enjoy learning about nature & .79 \\
\hline
\end{tabular}

$\alpha=.97$ 
Table 2

Factor analysis ${ }^{\mathrm{a}}$ of LCN, CNS and single item INS

\begin{tabular}{|c|c|c|c|c|}
\hline \multirow[t]{2}{*}{ Item $^{\mathrm{b}}$} & \multicolumn{4}{|c|}{ Factor loading } \\
\hline & 1 & 2 & 3 & 4 \\
\hline I often feel a sense of awe and wonder when I am in unspoilt nature $\mathbf{L C N}$ & .91 & & & \\
\hline $\begin{array}{l}\text { When I spend time in unspoilt nature I feel that my day-to-day worries } \\
\text { seem to dwindle away in face of the wonder of nature } \mathbf{L C N}\end{array}$ & .91 & & & \\
\hline I feel content and somehow at home when I am in unspoilt nature $\mathbf{L C N}$ & .90 & & & \\
\hline I often feel emotionally close to nature $\mathbf{L C N}$ & .88 & & & \\
\hline When in natural settings I feel emotionally close to nature. $\mathbf{L C N}$ & .88 & & & \\
\hline When I am close to nature, I feel a real sense of oneness with nature $\mathbf{L C N}$ & .86 & & & \\
\hline I feel joy just being in nature $\mathbf{L C N}$ & .83 & & & \\
\hline I feel a personal sense of interconnectedness with the rest of nature $\mathbf{L C N}$ & .82 & & & \\
\hline I feel a deep love for nature $\mathbf{L C N}$ & .82 & & & \\
\hline I feel that closeness to nature is important for my wellbeing $\mathbf{L C N}$ & .78 & & & \\
\hline I feel spiritually bound to the rest of nature $\mathbf{L C N}$ & .76 & & & \\
\hline I often feel a sense of oneness with the natural world around me CNS & .76 & & & \\
\hline Protecting the wellbeing of nature for its own sake is important to me $\mathbf{L C N}$ & .71 & & & \\
\hline $\begin{array}{l}\text { I need to have as much of the natural environment around me as possible } \\
\text { LCN }\end{array}$ & .71 & & & \\
\hline I often feel a strong sense of care towards the natural environment $\mathbf{L C N}$ & .70 & & & \\
\hline I enjoy learning about nature $\mathbf{L C N}$ & .69 & & & \\
\hline I think of the natural world as a community to which I belong CNS & .58 & -.35 & & \\
\hline I often feel part of the web of life CNS & & -.85 & & \\
\hline $\begin{array}{l}\text { I have a deep understanding of how my actions affect the natural world } \\
\text { CNS }\end{array}$ & & -.82 & & \\
\hline I feel as though I belong to the earth as equally as it belongs to me CNS & & -.81 & & \\
\hline $\begin{array}{l}\text { Like a tree can be part of a forest, I feel embedded within the broader } \\
\text { natural world CNS }\end{array}$ & & -.75 & & \\
\hline $\begin{array}{l}\text { When I think of my life, I imagine myself to be part of a larger cyclical } \\
\text { process of living CNS }\end{array}$ & & -.75 & & \\
\hline $\begin{array}{l}\text { I feel that all inhabitants of earth, human and nonhuman share a common } \\
\text { 'life force' CNS }\end{array}$ & & -.73 & & \\
\hline I often feel kinship with animals and plants CNS & & -.66 & & \\
\hline $\begin{array}{l}\text { I often feel like I am only a small part of the natural world around me and } \\
\text { that I am no more important than the grass on the ground or the birds in the } \\
\text { trees CNS }\end{array}$ & & -.52 & & .51 \\
\hline How interconnected are you with nature? INS & & -.51 & & \\
\hline I recognize and appreciate the intelligence of other living organisms CNS & & -.48 & & \\
\hline I often feel disconnected from nature CNS & & & .71 & \\
\hline $\begin{array}{l}\text { My personal welfare is independent of the welfare of the natural world } \\
\text { CNS }\end{array}$ & & & .69 & \\
\hline $\begin{array}{l}\text { When I think of my place on earth I consider myself to be a top member of } \\
\text { a hierarchy that exists in nature CNS }\end{array}$ & & & & .86 \\
\hline
\end{tabular}

\footnotetext{
${ }^{\mathrm{a}}$ Variance explained $=69.28 \% \quad \mathrm{KMO}=.96 \quad$ Bartlett's $=.000$

${ }^{\mathrm{b}}$ LCN Love and Care for Nature, CNS Connectedness to Nature Scale, INS Inclusion of Nature in Self.
} 
Table 3

Relationships $\left(r_{\mathrm{s}}\right)$ between LCN and frequency of pro-environmental behaviours

\begin{tabular}{|c|c|c|}
\hline Behaviour & $\begin{array}{l}\text { Love and Care } \\
\text { for Nature } \\
\text { (LCN) }\end{array}$ & Sample $^{\mathrm{a}}$ \\
\hline $\begin{array}{l}\text { How often do you make a special effort to buy products that are } \\
\text { environmentally friendly? }\end{array}$ & $.42 * * *$ & $\mathrm{~N}=245$ \\
\hline $\begin{array}{l}\text { How often do you make a special effort to buy paper and plastic } \\
\text { products that are made from recycled materials? }\end{array}$ & $.37 * * *$ & $\mathrm{~N}=244$ \\
\hline $\begin{array}{l}\text { How often have you boycotted or avoided buying the products of a } \\
\text { company because you felt that company was harming the environment? }\end{array}$ & $.51 * * *$ & $\mathrm{~N}=243$ \\
\hline $\begin{array}{l}\text { How often do you vote for a candidate in an election at least in part } \\
\text { because he or she is in favour of strong environmental protection/ } \\
\text { conservation? }\end{array}$ & $.48 * * *$ & $\mathrm{~N}=230$ \\
\hline $\begin{array}{l}\text { How often do you sign petitions in support of promoting protection of } \\
\text { the environment when they are presented to you? }\end{array}$ & $.44 * * *$ & $\mathrm{~N}=232$ \\
\hline $\begin{array}{l}\text { How often do you read newsletters, magazines or other publications } \\
\text { written by an environmental group? }\end{array}$ & $.40 * * *$ & $\mathrm{~N}=238$ \\
\hline $\begin{array}{l}\text { Indicate if you currently belong to or donate to an environmental } \\
\text { organisation? }\end{array}$ & $.32 * * *$ & $\mathrm{~N}=210$ \\
\hline
\end{tabular}

\footnotetext{
${ }^{\mathrm{a}}$ Variations in sample size due to missing values.

$* * * p<.001$
} 
Measuring love and care for nature 27

Table 4

Relationships ( $r$ ) between willingness to make sacrifices and three measures of connectedness

\begin{tabular}{|c|c|c|c|}
\hline $\begin{array}{l}\text { Willingness to make } \\
\text { sacrifices }\end{array}$ & LCN & CNS & INS \\
\hline $\begin{array}{l}\text { I would be willing to pay } \\
\text { much higher prices for many } \\
\text { goods and services in order to } \\
\text { protect the environment }\end{array}$ & $.60^{* * *}$ & $.51^{* * *}$ & $.38^{* * *}$ \\
\hline $\begin{array}{l}\text { I would be willing to accept } \\
\text { cuts in my standard of living } \\
\text { in order to protect the } \\
\text { environment }\end{array}$ & $.58^{* * *}$ & $.46^{* * *}$ & $.37^{* * *}$ \\
\hline
\end{tabular}


Measuring love and care for nature 28

Table 5

Love and care for nature (LCN), CNS and INS as predictors of people's willingness to make sacrifices to protect the environment. ${ }^{\mathrm{a}}$

Willingness to pay much higher prices for goods and services to protect the environment
Willingness to incur cuts in personal living standard to protect the environment

\begin{tabular}{|c|c|c|c|c|c|c|}
\hline Variable (predictor) ${ }^{\mathrm{b}}$ & B & SE B & $\beta$ & B & SE B & $\beta$ \\
\hline $\begin{array}{l}\text { Love and care for } \\
\text { nature LCN }\end{array}$ & 0.66 & 0.13 & $.46 * * *$ & 0.61 & 0.13 & $.43^{* * *}$ \\
\hline CNS & 0.01 & 0.01 & .06 & 0.01 & 0.01 & .06 \\
\hline INS & 0.09 & 0.07 & .08 & 0.09 & 0.08 & .09 \\
\hline $\mathrm{R}^{2}$ & & .32 & & & .29 & \\
\hline $\mathrm{F}$ & & $33.93 * * *$ & & & $29.37 * * *$ & \\
\hline
\end{tabular}

${ }^{\mathrm{a}}$ Collinearity statistics of Tolerance and VIF were well within acceptable limits.

${ }^{\mathrm{b}}$ Predictors entered into the analysis simultaneously.

$* p<.05 * * p<.01 * * * p<.001$ 


\section{References}

Callicott, J. B. (1993). Introduction. In M. E. Zimmerman, J. B. Callicott, G. Sessions, K. J. Warren \& J. Clark (Eds.). Environmental Philosophy: From animal rights to radical ecology (pp. 3-11). Englewood Cliffs, NJ: Prentice-Hall.

Campbell, D. T., \& Fiske, D. W. (1959). Convergent and discriminant validation by the multitrait-mutlimethod matrix. Psychological Bulletin, 56(2), 81-105.

Carson, R. (1965). The sense of wonder. New York: Harper and Row.

Clayton, S. (2003). Environmental identity: A conceptual and an operational definition. In S. Clayton \& S. Opotow (Eds.), Identity and the Natural Environment (pp. 45-65). Cambridge, MA: The MIT Press.

Cronbach, L. J., \& Meehl, P. E. (1955). Construct validity and psychological tests. Psychological Bulletin, 52(4), 281-302.

Degenhardt, L. (2002). Why do people act in sustainable ways? Results of an empirical survey of lifestyle pioneers. In P. Schmuck and P.W. Schultz (Eds.), Psychology of sustainable development (pp. 123-147). Boston, MA: Kluwer Academic Publishers.

De Vellis, R. F. (2003). Scale development: Theory and applications (2nd ed.). Thousand Oaks, CA: Sage Publications, Inc.

Dietz, T., Fitzgerald, A., \& Schwom, R. (2005). Environmental values. Annual Review of Environmental Resources, 30, 335-372.

Dietz, T., Ostrom, E., \& Stern, P. C. (2003). The struggle to govern the commons [Special issue]. Science, 302(5652), 1907-1912.

Dunlap, R. E., Van Liere, K. D, Mertig, A. G., \& Jones, R. E. (2000). Measuring endorsement of the New Ecological Paradigm: A revised NEP scale. Journal of Social Issues, 56(3), 425-442. 
Frantz, C., Mayer, F. S., Norton, C., \& Rock, M. (2005). There is no "I" in nature: The influence of self-awareness on connectedness to nature. Journal of Environmental Psychology, 25, 427-436.

Fromm, E. (1964). The heart of man: Its genius for good and evil. New York: Harper and Row.

Fromm, E. (1998). To have or to be? New York: The Continuum Publishing Company.

Hair, J. F., Black, W. C., Babin, B. J., Anderson, R. E., \& Tatham, R. L. (2006). Multivariate data analysis (6th ed.). Upper Saddle River, NJ: Pearson Prentice Hall.

Hepburn, R. W. (1984). 'Wonder' and other essays. Edinburgh: Edinburgh University Press.

Hinkin, T. R. (1995). A review of scale development practices in the study of organizations. Journal of Management, 21(5), 967-988.

Kaiser, F. G., Schultz, P. W., \& Scheuthle, H. (2007). The theory of planned behavior without compatibility? Beyond method bias and past trivial associations. Journal of Applied Social Psychology, 37(7), 1522-1544.

Kals, E., \& Maes, J. (2002). Sustainable development and emotions. In P. Schmuck and P. W. Schultz (Eds.), Psychology of sustainable development (pp. 97-122). Boston, MA: Kluwer Academic Publishers.

Kaplan, R., \& Kaplan, S. (1989). The experience of nature: A psychological perspective. New York: Cambridge University Press.

Kellert, S. R., \& Wilson, E. O. (Eds.). (1993). The biophilia hypothesis. Washington, DC: Island Press.

Kline, P. (1998). The new psychometrics: Science, psychology and measurement. London: Routledge. 
Klinger, E. (1998). The search for meaning in evolutionary perspective and its clinical implications. In P. T. P. Wong \& P. S. Fry (Eds.), The human quest for meaning: a handbook of psychological research and clinical applications (pp. 27-50). Mahwah, NJ: Lawrence Erlbaum Associates.

Leopold, A. (1949/ 1987). A Sand County Almanac. New York: Oxford University Press.

Marsh, H.W. (1996). Positive and negative global self-esteem: A substantively meaningful distinction or artifactors? Journal of Personality and Social Psychology, 70(4), 810-819.

Mayer, F. S., \& Frantz, C. M. (2004). The connectedness to nature scale: A measure of individuals' feeling in community with nature. Journal of Environmental Psychology, 24, 503-515.

Mayer, F. S., Frantz, C. M., Bruehlman-Senecal, E., \& Dolliver, K. (2009). Why is nature beneficial? The role of connectedness to nature. Environment and Behavior, 41(5), 607-643.

McMichael, A. J., Butler, C. D., \& Folke, C. (2003). New visions for addressing sustainability. Science, 302 (5652), 1919-1920.

Nisbet, E. K., Zelenski, J. M., \& Murphy, S. A. (2009). The nature relatedness scale: Linking individuals’ connection with nature to environmental concern and behavior. Environment and Behavior, 41(5), 715-740.

Nunnally, J. C. (1978). Psychometric theory (2nd ed.). New York: McGraw-Hill.

Orr, D. W. (1993). Love it or lose it: The coming biophilia revolution. In S. R. Kellert \& E. O. Wilson (Eds.). The Biophilia Hypothesis (pp. 415-440). New York: Island Press. 
Orr, D. W. (2004). Earth in mind: On education, environment, and the human prospect. Washington, DC: Island Press.

Osbaldiston, R., \& Sheldon, K. M. (2002). Social dilemmas and sustainability: Promoting people’s motivation to “cooperate with the future”. In P. Schmuck and P.W. Schultz (Eds.), Psychology of sustainable development (pp. 37-57). Boston, MA: Kluwer Academic Publishers.

Oskamp, S. (2002). Summarizing sustainability issues and research approaches. In P. Schmuck and P.W. Schultz (Eds.), Psychology of sustainable development (pp. 301 - 324). Boston, MA: Kluwer Academic Publishers.

Perrin, J. L., \& Benassi, V. A. (2009). The connectedness to nature scale: A measure of emotional connectedness to nature? Journal of Environmental Psychology, doi:10.1016/j.envp.2009.03.003.

Rolston, H. I. (1993). Biophilia, selfish genes, shared values. In S. R. Kellert \& E. O. Wilson (Eds.), The biophilia hypothesis (pp. 381-414). Washington DC: Island Press.

Schmuck, P., \& Schultz, P. W. (2002). Sustainable development as a challenge for psychology. In P. Schmuck and P.W. Schultz (Eds.), Psychology of sustainable development (pp. 3 - 17). Boston, MA: Kluwer Academic Publishers.

Schultz, P. W. (2000). Empathizing with nature: The effects of perspective taking on concern for environmental issues. Journal of Social Issues, 56(3), 391-406.

Schultz, P. W. (2001). The structure of environmental concern: Concern for self, other people, and the bioshpere. Journal of Environmental Psychology, 21, 327-339. 
Schultz, P.W. (2002). Inclusion in nature: The psychology of human-nature relations. In P. Schmuck and P.W. Schultz (Eds.), Psychology of sustainable development (pp. 61-78). Boston, MA: Kluwer Academic Publishers.

Schultz, P. W., Gouveia, V. V., Cameron, L. D., Tankha, G., Schmuck, P., \& Franek, M. (2005). Values and their relationship to environmental concern and conservation behavior. Journal of Cross-Cultural Psychology, 36(4), 457-475.

Schwartz, S. H. (1992). Universals in the content and structure of values: Theoretical advances and empirical tests in 20 countries. Advances in Experimental Social Psychology, 25, 1-65.

Seamon, D. (1984). Emotional experience of the environment. The American Behavioral Scientist, 27(6), 757-770.

Stern, P. C., Dietz, T., \& Guagnano, G. A. (1995). The New Ecological Paradigm in a social-psychological context. Environment and Behavior, 27(6), 723-743.

Stern, P. C., Dietz, T., \& Guagnano, G. A. (1998). A brief inventory of values. Educational and Psychological Measurement, 58(6), 984-1001.

Stern, P. C., Dietz, T., Abel, T., Guagnano, G. A., \& Kalof, L. (1999). A value-beliefnorm theory of support for social movements: The case of environmentalism. Human Ecology Review, 6(2), 81-97.

Suzuki, D. (1997). The scared balance: rediscovering our place in nature. Vancouver, BC: Allen \& Unwin.

Stokols, D. (1990). Instrumental and spiritual views of people-environment relations. American Psychologist, 45(5), 641-646.

Wilson, E. O. (1984). Biophilia. Cambridge, MA: Harvard University Press.

Wilson, E. O. (1993). The conservation ethic. In S. R. Kellert \& E. O. Wilson (Eds.), The biophilia hypothesis (pp.119-140). Washington DC: Island Press. 